\title{
MJN A COMPARISON OF FAMILY NEEDS AND RECEIVED CARE AS PERCEIVED BY FAMILY MEMBERS OF TRAUMATIC BRAIN INJURY PATIENTS
}

\author{
Ali Hamzah" ${ }^{1 *}$ Khemaradee Masingboon², Supaporn Duengpaeng² \\ ${ }^{1}$ Nursing Department of Bandung Health Polytechnic, Ministry of Health, Bandung, Indonesia \\ ${ }^{2}$ Adult Nursing Department, Faculty of Nursing, Burapha University, Chonburi, Thailand \\ *Corresponding Author’s Email: alihamzahbandung@yahoo.co.id
}

\begin{abstract}
Family members of traumatic brain injury (TBI) patients have commonly experienced high level of stress and uncertainty due to the patient's condition. To alleviate stress of family members, it requires providing care to fulfill family needs. Unfortunately, nurses often rarely assess the needs of family members. As a consequence nurses rarely provide the appropriate nursing care, and as a result the family needs are unmet. A comparative descriptive design was conducted to describe the needs of family members of TBI patients and to compare the family needs and the received care as perceived by family members based upon guiding from a family stress theory of the Double ABCX Model. 119 family members of TBI patients were recruited as the sample. The questionnaires used to obtain data consisted of a socio-demographic data and the Critical Care Family Need Inventory. Data were analyzed using descriptive statistics and the Wilcoxon signed-ranks test. The findings indicated that the assurance need category was the most important need of family members TBI patients, followed by information, comfort, proximity, and support need. The findings also indicated that there were significant differences between mean scores of family needs and mean scores of received care from nurses as perceived by family members of TBI patients. Therefore it can be recommended that nurses should improve their ability to identify and understand the needs of the family members during critical condition in hospital.
\end{abstract}

Keywords: Family Embers, Family Needs, Received Care, Traumatic Brain Injury Patients

\section{INTRODUCTION}

The families of moderate to severe TBI patients have commonly experienced high level of stress of losing their loved ones (Price et.al., 1991). Due to the sudden TBI, families typically experience fear associated with loss of control, uncertainty, and financial constraints (Fox-Wasylyshyn, El-Masri \& Williamson, 2005). The possibility of ongoing difficulty will further aggravate such stress. The accumulation of many stressful factors may lead to crisis conditions that can threaten family integrity and lose their ability to cope with the problem (Bond et al., 2003; Gavaghan \& Caroll, 2002; Van Horn \& Tesh, 2000; Verhaeghe et al., 2005).
It is quite general consensus that involving families in patient care is important and has positive effect on both families and patients. In this context, family members can have a great impact on the patients' general well-being by providing psychological and emotional stability. Families tend to be both reactors to family members' health problems and actors in determining their health problems. Therefore, family members are important people who should be involved in the decision making and therapeutic process from the state of being well to diagnosis, treatment and recuperation (Friedman, Bowden \& Jones, 2003).

To alleviate stress of TBI patients and to help their 
families cope with this crisis condition, it is required that the care providers also fulfill the family needs (Leung, Chien \& Mackenzie, 2000). Unfortunately, a large number of researches on healthcare practices have shown that the family members do not receive enough attention to what they need from health care professionals. The most mentioned reasons are that the nurses lack the understanding to prioritize the needs of patient's family (Bond et al., 2003; Verhaeghe et al., 2005).

As a consequence, nurses do not provide the appropriate nursing intervention to the family, and the family needs are unmet (Takman \& Severinson, 2004). This situation might lead to the occurrence of stress or crisis among family members (Van Horn \& Test, 2000). Thus, it is important to examine family needs and the care it receives from nurses as perceived by family members of TBI patients.

The purposes of this study are to describe the needs of family members of traumatic brain injury patients and to compare between the family needs and the received care from nurses as perceived by family members

\section{RESEARCH METHODOLOGY}

A comparative descriptive design was use to conduct this study at neurosurgical and general surgical wards of three hospitals located in different regions at Bandung, Indonesia. A total number of 119 family members of TBI patients who met the inclusion criteria participated in this study. The sample selection criteria were: 1) be older than 17 years of age and he/she voluntarily agreed to participate in the study through informed consent, 2) be a person who regularly provided cares to the patient during admission in hospital, and 3) be able to read and write Indonesian language.

The instruments used in this study consist of a Socio-demographic Data Form and the Critical Care Family Needs Inventory (CCFNI) questionnaire (Leske, 1991). The modified CCFNI used in this study consists of two parts. The first part represented the measurement of family needs. The respondent answered about perception of 45 family needs statements using 4 point Likert-type rating scale (not important $=1$, slightly important $=2$, important $=3$, and very important $=4$ ). The mean score ordinary of family needs was ranged from 1.00 to 4.00 . The higher score denotes that kind of needs were more important for family members. The second part, the same modified CCFNI was used to examine the extent of received care from nurses on each of a need statement. There are 45 needs statements using 4 point Likert-type rating scale (never $=1$, rarely $=2$, sometimes $=3$, and always or often $=4)$. The scores reflect whether or not the needs of family are met. In addition, the higher score denotes that needs of family were fulfilled by the care received from nurses; in other words, the needs of family were met. Since this study was conducted with Indonesian people, some of need statements of the CCFNI was modified to use with Indonesian context and culture. Furthermore, this instrument was translated to Indonesian version using translation-back-translation techniques (Jones \& Kay, 1992).

Data collections were conducted after the research proposal was approved by the ethical committee of Burapha University and ethical committee of three hospitals, in Bandung, Indonesia. Data analysis was divided into three major parts: 1) descriptive statistic including frequency, mean, and standard deviation (SD) were used to describe the demographic data, 2) descriptive statistic including mean and standard deviation were used to analyze the scores rank ordering of the family need and received care from nurses as perceived by family members of TBI patients, and 3) the Wilcoxon Signed Ranks test was used to determine the differences mean scores rank ordering of the family needs and received care as perceived by family members.

\section{RESULTS}

Subjects' characteristics consist of patient characteristics, particularly the severity of traumatic brain injury reported by using Glasgow Coma Scale (GCS) and family members characteristics including age, gender, educations level and average income of family, religion, times duration stay at hospital, past experienced, and relationship with the patient. A total number of 119 family members of TBI patients who met the inclusion criteria were recruited from general surgical and neurosurgical wards of three hospitals. Patients' characteristics consisted of 100 cases $(84 \%)$ of moderate TBI patients and 19 cases $(16 \%)$ of severe TBI patients.

While for the demographic characteristics of family members, family members ranged in age from 17 to 71 years old, with a mean age of 34.85 years and the 
standard deviation was 10.49. Fifty-nine family members $(49.6 \%)$ were of age 35 to 59 years. The majority of the family members were male $(61.3 \%)$, with low education level, elementary and junior high school (57.1\%) and low economic status which the average income was less than 750.000 rupiahs per month $(62.2 \%)$. Most of the family members were Moslem (95\%). Eighty-seven percent of the family members stayed in hospital ranged from 1 to 4 days, and most of them $(80.6 \%)$ did not have experiences of taking care of patients in critical conditions. Siblings of the TBI patients were the largest group of respondents $(35.3 \%)$ and thirty-seven percent of family members did not stay at the same home with the patient.

The Table presents the comparison of mean scores of family needs and received care from nurses as perceived by family members. The data indicate that the total mean score of the family needs was $3.38(\mathrm{SD}=$ 0.19 ) and total mean score of the received care from nurse was $2.66(\mathrm{SD}=0.32)$. There is a significant difference of mean scores between family needs and received cares from nurses as perceived by family members of TBI patients $(\mathrm{Z}=-9.41, P<0.001)$ with the mean scores of received care being lower than the mean scores of family needs.

Moreover, there are significant differences for each subcategory of family needs and received care from nurses as perceived by family members with the mean scores of received care is lower than the mean scores of family needs. The mean score of support needs is 3.15 and 2.31 for support received care $(Z=-9.42, P<0.001)$; the mean score of comfort need is 3.45 and 2.96 for comfort received care $(Z=-7.43, P<0.001)$; the mean score of information need is 3.45 and 2.64 for information received care $(\mathrm{Z}=-9.22, P<0.001)$; the mean score of proximity need is 3.44 and 2.74 for proximity received care $(Z=-9.28, \mathrm{P}<0.001)$; and the mean score of assurance need is 3.64 and 3.06 for assurance received care $(Z=-8.47, P<0.001)$.

The results also indicated that 41 of 45 need items $(91.1 \%)$ was significant different between mean scores of family needs and received care from nurses as perceived by family members of TBI patients. These findings reflected that the needs of family members were unmet. However, 4 need items were not significant different between mean scores of family need and received care from nurses as perceived by family members of TBI patients; in other words, these needs were met by family members, including the need: to get a bathroom near the wards of the patient $(Z=-.12$, $P>0.05)$, to get food store or restaurant that available to me while in the hospital $(Z=0.54, P>0.05)$, to have waiting place near the patient's wards $(Z=0.14, P>$ $0.05)$, and to stay near the patient at night $(Z=0.078, P$ $>0.05)$.

Table: Mean, standard deviation and comparison of the mean scores of family needs and received care from nurses as perceived by family members of TBI patients using the Wilcoxon signed-ranks test.

\begin{tabular}{|c|c|c|c|c|c|c|c|}
\hline \multirow{3}{*}{ No } & \multirow{3}{*}{$\begin{array}{l}\text { Subcategory and } \\
\text { Family Need Item }\end{array}$} & \multicolumn{4}{|c|}{$n=119$} & \multirow{3}{*}{$\boldsymbol{Z}$} & \multirow{3}{*}{$\boldsymbol{P}$} \\
\hline & & \multicolumn{2}{|c|}{ Family Need } & \multicolumn{2}{|c|}{ Received Care } & & \\
\hline & & $\bar{x}$ & $S D$ & $\bar{x}$ & $S D$ & & \\
\hline & A. Support needs & 3.15 & 0.27 & 2.31 & 0.41 & -9.42 & $0.000 * *$ \\
\hline 1. & $\begin{array}{l}\text { To get direction about what can be done by family } \\
\text { members at the bedside during waiting for the patient. }\end{array}$ & 3.40 & 0.53 & 2.39 & 0.96 & -7.79 & $0.000 * *$ \\
\hline 2. & To talk with nurses about negative. & 2.15 & 0.89 & 1.53 & 0.85 & -5.66 & $0.000 * *$ \\
\hline 3. & $\begin{array}{l}\text { To have nurses beside the patient when visiting the } \\
\text { critically ill. }\end{array}$ & 3.06 & 0.62 & 2.33 & 0.97 & -6.43 & $0.000 * *$ \\
\hline 4. & To have nurses who can give support. & 3.39 & 0.74 & 2.43 & 0.89 & -7.28 & $0.000^{* *}$ \\
\hline 5. & $\begin{array}{l}\text { To talk about the worst possibility of the patient's } \\
\text { condition. }\end{array}$ & 3.28 & 0.76 & 2.11 & 1.06 & -7.51 & $0.000 * *$ \\
\hline 6. & $\begin{array}{l}\text { To find a nurse who is concerned with the patie nt's } \\
\text { health }\end{array}$ & 3.71 & 0.49 & 3.14 & 0.69 & -6.45 & $0.000 * *$ \\
\hline
\end{tabular}




\begin{tabular}{|c|c|c|c|c|c|c|c|}
\hline 7. & $\begin{array}{l}\text { To find a nurse who could help financial problems of } \\
\text { the family members. }\end{array}$ & 3.22 & 0.75 & 2.49 & 1.05 & -6.59 & $0.000^{* *}$ \\
\hline 8. & $\begin{array}{l}\text { To have time that can be used to reduce family } \\
\text { members' stress. }\end{array}$ & 3.11 & 0.58 & 2.61 & 0.92 & -4.72 & $0.000^{* *}$ \\
\hline 9. & $\begin{array}{l}\text { To have opportunity to cry when the family members } \\
\text { feel sad. }\end{array}$ & 2.22 & 0.86 & 1.87 & 0.92 & -3.95 & $0.000 * *$ \\
\hline 10. & To be told about chaplain or "ustadz" services. & 3.38 & 0.58 & 1.63 & 0.98 & -8.82 & $0.000 * *$ \\
\hline 11. & To have "ustadz" or pastor visit. & 3.33 & 0.68 & 1.61 & 0.97 & -8.82 & $0.000 * *$ \\
\hline 12. & $\begin{array}{l}\text { To tal k with a nurse who could help with patients' } \\
\text { problems. }\end{array}$ & 3.34 & 0.64 & 2.63 & 0.77 & -6.76 & $0.000^{* *}$ \\
\hline 13. & $\begin{array}{l}\text { To talk with nurse } \mathrm{s} \text { who could help with family } \\
\text { members' problems. }\end{array}$ & 3.22 & 0.70 & 2.45 & .82 & -7.47 & $0.000 * *$ \\
\hline 14. & $\begin{array}{l}\text { To find a special place that can be used to calm down } \\
\text { feelings of the family members in the hospital. }\end{array}$ & 3.22 & 0.68 & 2.97 & 1.14 & -2.64 & $0.008^{*}$ \\
\hline 15. & $\begin{array}{l}\text { To have a nurse who can give explanation of the } \\
\text { environment before visiting the critically ill patient. }\end{array}$ & 3.21 & 0.54 & 2.47 & 0.87 & -7.00 & $0.000^{* *}$ \\
\hline & B. Comfort needs & 3.45 & 0.31 & 2.96 & 0.54 & -7.43 & $0.000 * *$ \\
\hline 16. & To feel accepted by hospital staff. & 3.58 & 0.50 & 3.39 & 0.75 & -2.49 & $0.013^{*}$ \\
\hline 17. & $\begin{array}{l}\text { To get a telephone facility in the ward that can be used } \\
\text { by family members. }\end{array}$ & 3.24 & 0.60 & 1.55 & 0.78 & -8.97 & $0.000^{* *}$ \\
\hline 18. & To get comfortable furniture in the waiting place. & 3.43 & 0.61 & 3.01 & 1.09 & -4.08 & $0.000 * *$ \\
\hline 19. & To have a bathroom near the ward of the patient. & 3.70 & 0.48 & 3.70 & 0.65 & -.12 & 0.905 \\
\hline 20. & $\begin{array}{l}\text { To get food store or restaurant available while in the } \\
\text { hospital. }\end{array}$ & 3.29 & 0.57 & 3.24 & 1.01 & -.54 & 0.587 \\
\hline 21. & $\begin{array}{l}\text { To be assured it is all right to leave the hospital for a } \\
\text { while. }\end{array}$ & 3.46 & 0.58 & 2.89 & 0.77 & -5.86 & $0.000^{* *}$ \\
\hline 22. & $\begin{array}{l}\text { C. Informations needs } \\
\text { To know which staff members could give information } \\
\text { and what type of information? }\end{array}$ & $\begin{array}{l}3.45 \\
3.50\end{array}$ & $\begin{array}{l}0.27 \\
0.55\end{array}$ & $\begin{array}{l}2.64 \\
2.82\end{array}$ & $\begin{array}{l}\mathbf{0 . 4 3} \\
0.89\end{array}$ & $\begin{array}{l}-9.22 \\
-6.20\end{array}$ & $\begin{array}{l}0.000 * * \\
0.000 * *\end{array}$ \\
\hline 23. & To know how the patient is being treated medically. & 3.70 & 0.50 & 3.22 & 0.82 & -5.39 & $0.000 * *$ \\
\hline 24. & To know why specific things were done for the patient. & 3.82 & 0.39 & 3.55 & 0.70 & -4.05 & $0.000 * *$ \\
\hline 25. & To know exactly what is being done for the patient. & 3.40 & 0.51 & 2.91 & 0.69 & -6.13 & $0.000 * *$ \\
\hline 26. & To know the expected outcome of the patient's care. & 3.49 & 0.50 & 2.28 & 1.02 & -8.13 & $0.000 * *$ \\
\hline 27. & To have the opportunity to talk with doctor every day. & 3.41 & 0.54 & 2.66 & 0.73 & -7.31 & $0.000 * *$ \\
\hline 28. & $\begin{array}{l}\text { To know about the types of staff members taki ng care } \\
\text { of the patient. }\end{array}$ & 3.14 & 0.60 & 2.33 & 0.92 & -6.68 & $0.000 * *$ \\
\hline 29. & $\begin{array}{l}\text { To have a specific hospital staff who can call home } \\
\text { when the family members are unable to visit hospital. }\end{array}$ & 3.13 & 0.70 & 1.41 & 0.79 & -9.02 & $0.000^{* *}$ \\
\hline
\end{tabular}




\begin{tabular}{|c|c|c|c|c|c|c|c|}
\hline & D. Proximity needs & 3.44 & 0.22 & 2.74 & .39 & -9.23 & $.000 * *$ \\
\hline 30. & To be able to help with the patient's physical care. & 3.38 & 0.55 & 2.69 & 0.92 & -6.18 & $.000 * *$ \\
\hline 31. & To have waiting place near the patient's ward. & 3.51 & 0.55 & 3.51 & 0.79 & -.14 & .891 \\
\hline 32. & To receive information about the patient once a day. & 3.81 & 0.42 & 2.93 & 0.71 & -8.11 & $.000 * *$ \\
\hline 33. & $\begin{array}{l}\text { To be told about discharge planning when nurses were } \\
\text { being made. }\end{array}$ & 3.29 & 0.53 & 1.71 & 0.98 & -8.92 & $.000 * *$ \\
\hline 34. & To have visiting hours changed for special conditions. & 3.19 & 0.53 & 2.52 & 0.9 & -6.18 & $.000 * *$ \\
\hline 35. & To stay near the patient at night. & 3.50 & 0.55 & 3.51 & 0.85 & -.078 & .938 \\
\hline 36. & To have visiting hours start on time. & 3.35 & 0.55 & 3.57 & 0.74 & -3.06 & $.002 *$ \\
\hline 37. & $\begin{array}{l}\text { To talk with the nurse who has responsibility take care } \\
\text { the patient every day. }\end{array}$ & 3.40 & 0.49 & 2.74 & 0.74 & -6.97 & $.000 * *$ \\
\hline \multirow[t]{2}{*}{38.} & $\begin{array}{l}\text { To be called at home about changes in patient's } \\
\text { condition. }\end{array}$ & 3.49 & 0.62 & 1.46 & 0.88 & -9.18 & $.000 * *$ \\
\hline & E. Assurance needs & 3.64 & 0.26 & 3.06 & .47 & -8.47 & $.000 * *$ \\
\hline 39. & To get honest answers. & 3.76 & 0.45 & 3.35 & 0.74 & -5.04 & $.000 * *$ \\
\hline 40. & To get understandable explanations. & 3.71 & 0.48 & 3.14 & 0.63 & -6.52 & $.000 * *$ \\
\hline 41. & $\begin{array}{l}\text { To know specific facts concerning the patient's } \\
\text { progress. }\end{array}$ & 3.45 & 0.50 & 2.74 & 0.73 & -7.40 & $.000 * *$ \\
\hline 42. & To feel that hospital personnel cared about the patient. & 3.52 & 0.52 & 3.18 & 0.76 & -4.11 & $.000 * *$ \\
\hline 43. & $\begin{array}{l}\text { To be assured that the best care possible is being given } \\
\text { to the patient. }\end{array}$ & 3.69 & 0.48 & 3.10 & 0.91 & -5.70 & $.000 * *$ \\
\hline 44. & To know the final result of the patient's cares. & 3.65 & 0.50 & 2.61 & 0.96 & -7.88 & $.000 * *$ \\
\hline \multirow[t]{2}{*}{45.} & To feel there is hope for the patient. & 3.73 & 0.46 & 3.27 & 0.83 & -5.06 & $.000 * *$ \\
\hline & Total & 3.38 & 0.19 & 2.66 & 0.32 & -9.41 & $.000 * *$ \\
\hline
\end{tabular}

$* P<0.05 ; * * P<0.001$

\section{DISCUSSION}

The findings present for overall 45 items mean score of the family needs was $3.38(\mathrm{SD}=0.19)$ and total mean score of the received care from nurse was $2.66(\mathrm{SD}=$ 0.32 ). There is a significant difference between mean scores of family needs and received care from nurses as perceived by family members of TBI patients $(Z=-9.41$, $P<0.001)$. There are also significant different for each subcategory of family needs and received care from nurses as perceived by family members. The mean scores of received care from nurses were lower than the mean scores of family members' expectation to their needs.

This finding is congruence with the result of previous studies. On the previous studies, family members were consistently ranked by their needs higher than the registered nurse did and there was a discrepancy between family members' expectations and their received care from actual intervention of the nurses (Lee \& Lau, 2003; Fox-Wasylyshyn, El-Masri \& Williamson,
2005; Leung, Chien \& MacKenzie, 2000; Gavaghan \& Caroll, 2002; Takman \& Severinson, 2004).

The discrepancies between family expectation of their needs and what they received from nurses of this study can be caused by two factors which are characteristics of family members and nurses' experiences in their job.

Characteristic of the family members. In this study, the family members had specific characteristics, such as: most of them were male, low education and low socio-economic level, never had experiences of taking care of the critical ill patients, be Moslem, and Sundanese. It is quite possible that the understanding, perception, and expectation of the family members to their needs as well as to the received care from nurse in this study were different from other studies. Therefore, the result of this study presented by overall of 45 items and five subcategories of family needs found significant difference between the family needs and the received cares from nurse as perceived by family members. 
Nurses' experiences. Nurse experienced to take care of the patient in the critical care unit is one factor that can influence to understand and to fulfill the need of family members. According to the study of Takman \& Severinson (2004), they found that registered nurses who have longer experience in critical care unit are more sensitive to significant others' or family members' problem when informing and listening, more understand to the need ' to know what is going on', and more have attention to perceived the need of family members.

In this study, even though the relationship between nurses' experience and the need of family members is not examined, the finding of previous study can be considered as one factor that has influenced the result of this study which indicates that there are significant differences between family needs and the received cares from nurses. Ironically, 41 of 45 need items (91.1\%) showed significant differences between family needs and received care from nurses as perceived by family members of TBI patients or in other words most of the family needs were unmet by the provisional care from nurses. There were only 4 need items that family needs met with their needs from nursing cares as perceived by family members of TBI patients. Furthermore, three of four need items that family members met with their needs came from hospital facility, including the need: to have a bathroom near the wards of the patient, to get food stores or restaurant and to have waiting place near the patient's wards.

These findings were very important for nurses to be concern more about family needs. Nurses should have more attention and understanding about family needs by developing some programs that can meet the needs of family members of TBI patients. Following these findings, nurses should provide assurance need that could make family feel safe and convinced with the best possible care to their beloved one; provide honest and understandable information of the patient's condition every day; demonstrating good attitude that can make family members feel comfortable; maintain closeness among family members and the patients by involving family members in some nursing interventions.

\section{CONCLUSION}

According to result, conclusion to this study was that the family members reported all of the 45 need items to be important and very important needs. Meanwhile, the received care from nurses was rated rarely or just sometimes met to family needs. The assurance need category was the most important need of family members of TBI patients, followed by information need, comfort need, proximity need, and support need. There were significant differences between the mean scores of family needs and the mean scores of received care from nurses as perceived by family members of TBI patients.

Result of this study has implication for health care policy of hospital, nursing practice, nursing education, and for further research study, as follows: the finding of this study can be used extensively to identify needs of the family members and develop appropriate nursing intervention based on their needs. An educational program related to the information about family needs should be developed for family members of TBI patients, for example information about the patient condition, diagnosis, treatment plan, signs and symptoms, and prognosis. The family members also should be given opportunity to talk with the doctor or nurse at least once times a day. Several strategies are effective in meeting information needs of family members, such as: using instructional material or leaflet, communication boards, a designated contact person, and family meeting or rounds.

The findings of this study indicate that nurses should improve their ability to identify and understand needs of the family member during critical condition in hospital, thus, topic about family needs must be considered to add in nursing curriculum as a part of subject matter. Moreover, institutional nursing education can make cooperation with human resource development unit of hospital to develop some program and encourage some subject matters that can improve nurses' understanding about family needs of the critical ill patients. Several programs can be created which is appropriates with nurses' necessity, such as: in service training about family needs and family centered-care, and continuing education.

The finding of this study can also be used as a preliminary data to develop further research that has relationship with this topic in Bandung, Indonesia. There is a need to understand more about the relationship between family needs and demographic factors, so that conducting research to examine relationship among those factors is recommended. Moreover, there is the need to explore more family members' experience and nurses' experience during 
they take cares the critical ill patients based their own perspective, therefore qualitative study for further research is needed to conduct.

\section{ACKNOWLEDGEMENT}

I would like to express my sincere gratitude and deep appreciation to Dr. Khemaradee Masingboon, and Dr. Supaporn Duangpaeng, also to all experts involved in validating the instrument, Assist. Prof. Dr. Wanlapa Kunsongkeit, Dra. Anah Sasmita, BSN. M.Kep., Ahmad Yamin, BSN. M.Kep. Sp.Com.,
Kusman Ibrahim, BSN. M.N.S. and Lia Nugraha, BSN.

I also would like to thank for the Director and the head nurse of neurosurgical and surgical wards of three hospitals, in Bandung, Indonesia, who give me permission to conduct research. I am gratefully indebted for all of family members of traumatic brain injury patients who participated in this study Great appreciation to Department of Health of Indonesia Government which take responsibility our funding for this research.

\section{REFERENCES}

Bond, A.E., Draeger, C.R., Mandleco, B. \& Donnelly, M. (2003). Needs of family members of patients with severe traumatic brain injury. Critical Care Nurse, 23 (4), pp 63-72.

Fox-Wasylyshyn, S.M., El-Masri, M. M. \& Williamson, K.M. (2005). Family perceptions of nurses' roles toward family members of critically ill patients: A descriptive study. Heart \& Lung, 34 (5), pp 335-344.

Friedman, M., Bowden, V. \& Jones, E.G. (2003). Family nursing: Research, theory, \& practice (5 $5^{\text {th }}$ ed.). Pearson Education Inc, New Jersey.

Gavaghan, S. R. \& Carroll, D.L. (2002). Families of critically ill patients and the effect of nursing interventions. Dimensions of Critical Care Nursing, 21(2), pp 64-71.

Jones, E.G. \& Kay, M. (1992). Instrumentation in cross-cultural research. Nursing Research, 41 (3), pp 186-188.

Lee, L.Y.K. \& Lau, Y. L. (2003). Immediate needs of adult family members of adult intensive care patients in Hong Kong. Journal of Clinical Nursing, 12 (4), pp 490-500.

Leske, J.S. (1991). Internal psychometric properties of the critical care family needs inventory. Heart \& Lung, 20(3), pp 236-244.

Leung, K.K., Chien, W.T. \& Mackenzie, A.E. (2000). Needs of Chinese families of critically ill patients. Western Journal of Nursing Research, 22(7), pp 826-840.

Price, D.M., Forrester, D.A., Murphy, P.A. \& Monaghan, J. F. (1991). Critical care family needs in an urban teaching medical center. Heart \& Lung, 20(2), pp 83-188.

Takman, C.A. \& Severinson, E. (2004). The needs of significant others within intensive care-the perspective of Swedish nurses and physicians. Intensive and critical Care Nursing, 20(1), pp 22-31.

Van Horn, E. \& Tesh, A. (2000). The effect of critical care hospitalization on family members: Stress and responses. Dimensions of Critical Care Nursing, 19 (4), pp 40-49.

Verhaeghe, S., Defloor, T., Van Zuuren, F., Duijnstee, M. \& Grypdonck, M. (2005). The needs and experiences of family members of adult patients in an intensive care unit: A review of the literature. Journal of Clinical Nursing, 14(4), pp 501-509. 